Jan Johansson, Lena Abrahamsson, Birgitta Bergvall Kåreborn, Ylva Fältholm, Camilla Grane, Agnieszka Wykowska*

\title{
Work and Organization in a Digital Industrial Context ${ }^{* *}$
}

There are clear signs that digitalization attempts such as Industry 4.0 will become more apparent in workplaces. This development requires reflections and considerations so we do not create more problems than we solve. In our paper, we have raised several questions related to the Industry 4.0 that need answers: Is Industry 4.0 a discourse, an organizational model, or just technology? Does the requirement for flexibility call for a new labour market? How will Industry 4.0 affect competence and skill requirements? Will Industry 4.0 encourage a new gender order? Will Industry 4.0 take over dangerous routine work or will old work environmental problems appear in new contexts and for other groups of workers? Can we rely on robots as work mates or will they spy on us and report to management? Based on our analysis, we addressed four knowledge gaps that need more research in relation to the digitalization of work: The relationship between new technology, working conditions, qualifications, identity, and gender; the future of the workers' collective; crowdsourcing in an industrial context; and human-machine interaction with a focus on integrity issues.

Key words: Work, Organization, Labour, Gender, Industry 4.0, Internet of Things (JELcodes: J16, J21, J22, J23, J24, J25, J54, J80, M15, M54, O14)

\section{Introduction}

The wolf is coming or God's gift to mankind are two expressions that follow many technical innovations, but perhaps especially digitalization and computerization. The wolf is coming indicates a fear that our lives will be deprived of something we want to maintain while we neither can nor really want to refrain from the computerized society. God's gift to mankind emphasizes the advantages and new opportunities that facilitate and enrich our lives. Society has participated in the technological development with these mixed emotions over the last 20 years and now there are clear signs digitalization will take a greater leap into not only our everyday lives but also our work lives in very concrete ways. This article discusses this technological

* Jan Johansson, Lena Abrahamsson, Birgitta Bergvall Kåreborn, Ylva Fältholm, Camilla Grane, and Agnieszka Wykowska, Luleå University of Technology

Corresponding author: Professor Jan Johansson, Human Work Science, Luleå University of Technology, 97187 Luleå, Sweden, Email: Jan.Johansson@ltu.se, Phone: +46 70-5593039

** Article received: October 6, 2016

Revised version accepted after double blind review: June 8, 2017

mrev, 28 (3) 2017, $281-297$ 
development by examining Swedish experiences and formulates some areas for further research.

\section{Industry 4.0}

A current example of the technological development is presented in Industrie 4.0, a strategy shaped by the German government in 2013 (www.plattform-i40.de). The technical core is automation that now through digitalization is lifted to a new level where technical components can be integrated and autonomous machines can be linked to autonomous factories. Industry 4.0 is described as the next great industrial revolution. This revolution consists of an implementation of "Internet of Things, Humans, and Services" where the entire production process is included in Internetbased networks. The concept is formulated in the report Recommendations for implementing the strategic initiative Industrie 4.0 - Final report of the Industrie 4.0 Working Group (Kagerman, Wahlster, \& Helbig, 2013). A similar concept is General Electric's Industrial Internet.

The Swedish government has recently presented its strategy for digitalization of the industry in the report Smart Industry - a strategy for new industrialisation for Sweden (Regeringskansliet, 2016). The strategy, inspired by the German's Industry 4.0, accepts the belief that we are facing "the fourth industrial revolution". As with the steam engine, electricity, and electronics in earlier ages, today embedded and connected systems will save Sweden. The Swedish government identifies five strategy areas:

- Stimulating the development, spread, and use of the digital technologies that have the greatest potential to lead the industrial sector's transformation.

- Exploiting the potential of digitalization broadly, irrespective of industry, company size, and geographical location.

- Encouraging new business models and organisational models in order to tap the potential of the new technology.

- Meeting new knowledge requirements that are brought about by digital development.

- Adapting framework conditions and infrastructure to the digital era.

The German vision paints a bright picture of the future industry where through the integration of software from product development and production we can link the virtual and the physical worlds into a powerful whole where the machines in the factories could begin to perform calculations and not just "physical work" (Gill, 2014; Lasi, Fettke, Kemper, Feld, \& Hoffmann, 2014). This is described as the Cyber-Physical Systems - or even socio-cyber-physical system - in which smart machines, smart materials, smart warehouses, and other smart systems in factories continuously exchange information with each other as well as with human workers. 
Similar and related concepts are the factory of the future, smart manufacturing, cloud manufacturing, the social enterprise, and the enterprise 2.0. The German strategy highlights the potential for skills development and a richer working life with more challenging work tasks. Kagerman et al. (2013) note that it is important for companies to have a socio-technical approach where workers' participation in job design is central. Several articles argue for Industry 4.0 as a flat organisation with more organisational innovations, learning, enhanced human-machine interaction, and a more human-centred view on the new technology as core tasks for the success of industrial production in the future (cf. Dombrowski \& Wagner, 2014; Kopacek, 2016; Lee, Kao, \& Yang, 2014). Yao, Jin, and Zhang (2015) promote the idea of "wisdom manufacturing" where things, computers, and humans (i.e. ubiquitous, artificial, and collective intelligence), as well as explicit and tacit knowledge, are integrated as a whole. Stock and Seliger (2016) argue that the development towards Industry 4.0 provides huge opportunities for the realization of sustainable manufacturing. At the same time, the German strategy also emphasizes the reduced need for the number of employees and functions as remote controls and preventive maintenance will inevitably reduce labour costs while increasing the security of the factory staff (Kagerman et al., 2013; Lee et al., 2014).

The Swedish vision is, if possible, even more positive than the German vision. In addition to the expected impact on growth and welfare, the Swedish vision argues that Industry 4.0 creates an innovative and sustainable industrial production that is environmentally friendly and provides the conditions for an attractive workplace. In contrast to its German role model, the reduced need for employees is not mentioned. On the contrary, it emphasises the creation of new jobs.

According to Industry 4.0, the industrial worker will be an expert who makes sure that production runs smoothly. The worker may no longer be "locked" in a control room; instead the real-time process data and status of machines follow the worker as she moves around the factory. She can solve problems on the spot by remotely interacting with other production operators, experts, suppliers, or customers in multicompetent teams or she can interact with a humanoid robot that assists in decisionmaking and analyses. Production control can be done in a digital model far away from the factory. In short, the augmented worker has extended senses and extended memory through technology that takes advantage of and supports human skills, increasing situational awareness, for example, through sensors embedded in the operator's clothes while keeping an uninterrupted operational vigilance.

Romero et al. (2016), using the technical core of Industry 4.0, forms a typologization of the future operators, Operator 4.0. Operator 4.0 is built on eight characteristics that can be seen as the core of the new technology: Super-Strength Operator (physical interaction) using biomechanical support for increased limb movement, increased strength, and endurance; Augmented Operator (cognitive interaction) using Augmented Reality (AR) for integrating information from the digital to the 
physical world; Virtual Operator (cognitive interaction) using Virtual Reality (VR) for simulation and training of real situation that might contain risks; Healthy Operator (physical and cognitive interaction) using wearable sensors for monitoring health-related metrics as well as GPS location; Smarter Operator (cognitive interaction) using Intelligent Personal Assistant (IPA) for interfacing with machines, computers, databases, and other information systems; Collaborative Operator (physical interaction) using Collaborative Robots (CoBots) for performing repetitive and non-ergonomic tasks; Social Operator (cognitive interaction) using Enterprise Social Networking Services (E-SNS) for interaction between operators and between operators and Internet of Things; and Analytical Operator (cognitive interaction) using Big Data Analytics for discovering useful information and predict relevant events. The classification points to the numerous possibilities of integrating Industry 4.0 with human labour - some good and some bad.

\section{Industry 4.0 and the Organizational Discourse}

Industry $4 . \mathrm{O}$ can be discussed in relation to the complicated patterns and contradictory trends that can be seen in the rich flora of management models or even management fashion spreading across the world during the $1980 \mathrm{~s}$ and $1990 \mathrm{~s}$ (see Furusten, 1999; Røvik, 2000). More models were added during the $2000 \mathrm{~s}$ and 2010 s, but with a narrower focus on Lean Production. The original impulses for these models often came from Japan, but their more prominent advocates were American researchers and consultants (Furusten, 1999). Compared with the North European traditions and the sociotechnical approaches of the $1970 \mathrm{~s}$ and $1980 \mathrm{~s}$, which were based on bottom-up and workplace perspectives, these models had a clear management and top-down perspective focusing on individualization and similar normative messages. Even if reality has been more stable and slow than the organisational fashion, the models played a significant role at the discourse level and still influence power systems and the social constructions in organisations - how people view the organisation, the profession, the work, and themselves as workers (Abrahamsson, 2009; Johansson \& Abrahamsson, 2009).

Lean, still the dominant organisational model, is driven by higher demands of individualized and customized products and services, an approach that focuses on processes, creativity, and innovation and on temporary and liquid forms of organisation. Typical of the $2010 \mathrm{~s}$ is also the technology optimism, a phenomenon that seems to recur cyclically in organisational fashion. For example, the concept Business Process Re-engineering (BPR) was quite popular during the mid-1990s and typical for the period between Lean 1.0 and Lean 2.0 (Johansson, Abrahamsson, \& Johansson, 2013). Like Industry 4.0, BPR is process- and customer-oriented and the ideas of work organisation are flexible, multi-competent, and autonomous teams organized around the production flows. Re-engineering stands for a radical transformation of the entire organisation and all work processes (Hammer \& Champy, 1993). 
The idea was to build a totally new kind of organisation based on the emerging information technology. Although this approach was pre-Internet, we can easily recognize the same optimistic views on computerised networks as in Industry 4.0.

Industry 4.0, essentially a technology-driven vision, generally refers to a technological revolution with a strong focus on production rationalization, but we can also see that the organizational recommendations provided by Kagerman et al. (2013) and others set up for the implementation of Industry 4.0 (e.g. production flow, connected processes and systems, horizontal integrated and flexible organisation, learning and production standardization, and diagnosis) have clear similarities with $B P R$, The Boundaryless Organisation, Learning Organisation, TBM, TQM, Six Sigma, and Lean. Therefore, there is a need for critical organisational analyses, discourse analyses, analyses of embedded conflicts in Industry 4.0, power shifts, and invisibility of power. In addition, there is a need for analyses related to other current organizational trends (e.g. centralization, monitoring, requirements for voluntary, storytelling, and corporate branding) and wider social changes.

\section{Labour Flexibility and Global Sourcing of Labour}

Over the years we have witnessed an increase in labour flexibility, the decline of standard labour contracts, the sub-contracting or outsourcing of work (Taylor, 2010), increasing self-employment, and mounting insecurity (Thompson, 2013).

The introduction of Industry 4.0 brings together the manufacturing and the IT sector, two relatively distinct occupational groups. The consequences this merger will have on work and employment conditions, competence, skills, roles, responsibilities, and labour sourcing strategies are still unclear.

However, analysing past and present changes in the IT sector might guide us in what we can expect when it comes to the employment and working conditions for the employees of future Industries 4.0 since it is digital infrastructures, smart devices, together with the collection and analyses of big data that are expected to bring about the transformation. This reveals a number of emerging trends such as the introduction of Internet of Things, the pervasive use of social media, and the realisation of value embedded in big data. However, it is the use of digital platforms by global enterprises to crowd-source labour to small and micro sized companies all over the world that is reshaping work and employment conditions in the most visible way so far.

The term crowdsourcing was coined by Howe in 2006 and was presented as a new level of outsourcing. For example, rather than relying on offshore jobs at low-cost locations, companies can outsource functions once performed by employees to an amorphous and generally large pool of individuals using an open call over the Internet (Howe, 2008). The most significant differences between crowdsourcing and a traditional workforce are the higher levels of flexibility, scalability, access to a broad 
range of skills, and experiences at significantly less cost, coupled with the lack of employment regulations. This strategy appeals to industrial firms as they are able to access a labour force that can expand and contract on demand without any significant transaction costs or logistical hurdles. Management control is simultaneously 'at a distance' while remaining all-powerful when directing work tasks and determining the nature of reward. Relationships are fleeting and largely anonymous, with no obligation to provide support or facilities for the workforce.

\section{Organisation, Competence, and Skill}

The visions of fully automated factories, Industry 4.0, and Internet of Things not only change the technological landscape of industrial workplaces and organizations, but also cause a qualitative knowledge transformation - from bodily and tacit into more abstract and theoretical knowledge and skills. In the optimistic view, we can read that Industry 4.0 requires workplace learning as well as continuous education and systems that make use of the workers' skills - i.e. a learning organization. Using Kern and Schumann's concepts (1974), we can see a clear transformation from the craftsman-like qualification into more technical qualifications. The new demands for teamwork, responsibility, and comprehensive understanding of production flow can be seen as a movement from qualifications dependent on the process to qualifications more independent of the process (cf. Kern \& Schumann, 1974, 1987; Bright, 1958; Blauner, 1964; Johansson, 1986). What was earlier the workers' tacit knowledge (Polanyi, 1967) will be formalised into theoretical knowledge, digitalized, and used in computers and smart phones. In this transition, we can see contradictory movements of upskilling (rapidly changing skill demands and more theoretical, comprehensive, and communication tasks) and deskilling (fragmentation of individual craft knowledge and whole tasks) (Abrahamsson \& Johansson, 2006).

Whether it is a question of upskilling, deskilling, or reskilling, the transformation of knowledge affects workplace cultures, community of practices, and identities (cf. Wenger, 1998; Fenwick, 2005). Individuals and organizations will have to create and recreate qualifications, identity, and gender when meeting new technology in a changing context. For example, the new knowledge and skills needed may be more abstract and theoretical, but still based on bodily and tacit knowledge although in new and less physically demanding forms. A common optimistic scenario gives women and other previously underrepresented groups a chance to enter and master different types of industrial work such as in mining and process industries. Given that this scenario is realized, it does not entail a smooth and unproblematic process. The identity and symbolic aspects of work often lag behind the developments in, for example, technology and qualification demands, resulting in restoring responses during processes of organisational changes (Abrahamsson, 2014). As the workers' collective (cf. Lysgaard, 1961; Fältholm, 1998) is built and sustained by processes of homosocial interaction and identification and on norms controlling likeness be- 
tween workers, there is reason to investigate how new technology affects these processes. The seemingly robust gender and power relations will be challenged, renegotiated, and ultimately transformed.

\section{Gender}

One of the hopes of the technological development in the industry is that it will allow for changed gender patterns: a better work environment combined with higher qualification demands will enable more women to work in the industry, creating better gender equality. But the picture is not so clear-cut. At many industrial workplaces where digitalization is taking place as well as at existing IT-workplaces (e.g. programming and gamification), it is quite common that technology is associated with masculinity (Berner, 2003; Mellström, 2004). This masculinization of technology is evident in the discourse of the technology as well as in the culture of these companies. At traditional male-dominated industrial workplaces, such as mining, even if the workplaces undergo digitalization, the connection to masculinity lingers because of the old strong symbolic links to a traditional blue-collar masculinity (Abrahamsson, 2006; Andersson, 2012; Eveline, 2001; Lahiri-Dutt, 2007; 2012; see also Collinson, 1992; Whitehead, 2002; Willis, 1979). For example, the mine is often associated with explicit expressions of a special type of masculinity, "machomasculinity", which is almost difficult to take seriously and analyse (Somerville \& Abrahamsson, 2003). The fear of being seen as less masculine is a common theme in these kinds of workplaces. Here men, more than in other workplaces, find it difficult to be associated with competences, attitudes, or behaviours that have a female gender-code (Eveline, 1989; 2001; Gherardi \& Nicolini, 2000; Ely \& Meyerson, 2008; Somerville \& Abrahamsson, 2003) or have associations with unmanliness (Connell, 1995). As a result, we can see an interesting and seemingly paradoxical tendency that workplaces and work tasks introduced as a result of automation, computerization, and robotization can undergo a process of "feminisation" while the men hang on to the old technology (Olofsson, 2010). One example of this is when the mining workers underground, half-jokingly give the remote-control workers sitting above ground nicknames such as "the velour workers" (Abrahamsson \& Johansson, 2006; Andersson, 2012). On the one hand, this trend opens up for new gender constructions in industry; on the other hand, this trend can be seen as a symptom of a conservative organization, i.e. barriers to implementing the new technology and therefore important to study and understand.

At workplaces with a more gender-balance, male workers may attempt to restore the existing local gender order by telling macho-masculine stories, refusing to do 'women's work' or 'womanish work', and openly resisting women at the workplace (Abrahamsson, 2009; Eveline \& Booth, 2002; Lahiri-Dutt, 2012). In these work places, ideas about gender - femininities and masculinities - often are so conservative they 
can create trouble during organizational changes and the implementation of new technology (Abrahamson, 2009; Hollway, 1996; Collinson \& Hearn, 1996).

Gender is something people do and construct in social interactions (Gherardi, 1994; West \& Zimmerman, 1987; 2009), embedded in work identities, work organisations, and technology (Acker, 1990), formed by complex societal processes and notions of masculinity and femininity. Many attitudes, norms, and cultural symbols at work that are learned through workplace socialization are connected to gender and the (unequal) gender order (Hirdman, 1988; 2001). Tacit collective agreements and a continuous dramatization of gender both restore and change our ways of seeing masculinity and femininity. According to Butler (1990; 1993), this play doesn't become really visible unless the existing masculinity and femininity are threatened (cf. Lindgren, 1985), such as in the transformation towards a digital industrial context. Even if such processes often are connected to the restoration of the unequal gender order they are situated in, these processes are continuously changing and there is a possibility to challenge and transform these processes (Abrahamsson, 2014).

\section{Work Environment}

In the optimistic visions of Industry 4.0, smart systems, automation, and remote control will take over dangerous as well as routine work so that production personnel can focus on learning, creating, and valuing work tasks in a safe environment (Gill, 2014). Even if the development will not be as the positive visions predict, depending on how the new technology is developed and interpreted, there will most likely be new types of industrial work, new types of work environments, and thus new work environmental problems. For example, digital technology and remote control together with the emerging global and sometimes boundary-less work not only results in increased freedom to decide how and where to work but also results in higher demands of availability, perhaps 24 hours a day, seven days a week. This change may blur the boundaries between work and private life. Moreover, since the ability to control and monitor the individual increases, there will be a risk of new psychosocial stress. An increased information flow and accessibility could also lead to anxiety and job strain (Hoonakker \& Korunka, 2014).

Other examples come from enhanced possibilities of production distribution, decentralisation, and outsourcing, both locally/regionally and in the global context. This creates dynamic systems of contractors, agency staff, and other actors temporarily active in the same physical workplace or in the same virtual/digital workplace. As mentioned above, the employment form as we know today might dissolve and be replaced with crowd sourcing and what can be called liquidised employment (Holtgrewe, 2014), complicating the coordination of work environment interventions and responsibilities (Johansson, Johansson, \& Abrahamsson, 2010). 
We might also expect that old work environmental problems will appear in new contexts and for other groups of workers. Some workers may participate in shaping the systems while others will become machine assistants or handle the repetitive and low qualified work tasks that could not be integrated into the automated and smart systems and the learning organisation. Maybe it is time to revive the old debate about the A and B teams (Braverman, 1974; Kern \& Schumann, 1974)?

\section{Human-Machine/Robot Interaction}

Industry 4.0 not only means almost invisible automated systems but also workplaces with robots and interactive machines inhabiting the traditional work space inhabited with people. Digitalization also represents an opportunity to empower the human by providing information that builds knowledge and understanding and gives them 'super powers' and possibilities to wider communication (Feki, Kawsar, Boussard, \& Trappeniers, 2013).

One step in this direction is information systems built on sensors that are worn by humans, so-called Wireless Body Area Networks (WBANs) or Body Area Sensor Networks (BASNs). Three sensors are typically included in a WBAN or BASN: physiological sensors measuring pulse, temperature, etc.; biokenetic sensors measuring posture and body movements; and ambient sensors measuring environmental factors such as temperature or sound pressure level (Johny \& Anpalagan, 2014). These systems could be useful as a preventive safety system for operators working in harsh environments (Alam \& Hamida, 2014). At the same time, one must be aware that these systems are a threat against the personal integrity.

The combination of robotics with Artificial Intelligence (AI) is another step in this direction. In fact, a science-fiction dream of friendly robots as workmates may soon become our reality (Breazeal, 2002). However, one of the key issues that need to be addressed in this endeavour is whether and how humans can accept robots. Researchers in human-robot interaction (HRI) have focused on several factors that might influence the acceptance of robots as social companions: physical appearance (Bartneck, Kulic, \& Croft,, 2009), emotional expressiveness (Embgen et al., 2012; Kühnlenz, 2013), nonverbal communication modalities (Gonsior et al., 2011), explicit communication (Bickmore \& Cassell, 1999; Mattar \& Wachsmuth, 2012), repertoire of social gestures (Häring, Eichberg, \& André, 2012; Cabibihan, So, Saj, \& Zhang, 2012), and gender (Nomura, Suzuki, Kanda, \& Kato, 2006). Yet, very little progress has been made in the systematic study of social attunement (i.e. a well-functioning and human-like communication between humans and robots with the use of objective measures as developed by social cognitive neuroscience).

\section{Addressing Knowledge Gaps}

There are many questions that must be cleared along with the introduction of Industry 4.0 and Internet of Things. The development cannot and should not be 
stopped, but it requires reflection and consideration so we do not create more problems than we solve. Based on our analyses and the literature review above, we have identified four research fields where we see a need for new perspectives, approaches, and analyses.

\section{Technology, Working Conditions, Qualifications, Identity, and Gender}

One such area is how technology and technological development are related to working conditions, qualifications, identity, and gender. There is a strong tradition of analysing technology and technological development based on German industrial sociology (cf. Kern \& Schumann, 1974; Köhler, 2016) and the American/British Labour process theory (Braverman, 1974). Although work and qualifications are central in both traditions, they need to be adapted to the new conditions and updated with modern research. Since the concepts of identity and gender are poorly represented in both traditions, we see a need for further research. Industry 4.0 and Internet of Things create a new arena for asking questions about technology's relation to work and working conditions. These questions entail a development of empirically-based methods for analysing the relationships between technology, qualifications, identity, and gender.

\section{The workers' collective}

Another field of research is related to Scandinavian industrial sociology. In this field, Lysgaard's (1961) book on the workers' collective is regarded as seminal, one of the classics of its time. Although it is well researched and documented that workers act collectively in the workplace, the term 'workers' collective' is rarely used in current Nordic research (Hasle \& Sörensen, 2013). It is, for example, well-known that the workers' collective functions as a set of norms, controlling the workers' relations to each other as well as the extent to which deviations from these norms (e.g. a certain type of masculinity, negative attitudes to management, and technological change) are counteracted or accepted. Materialized by this normative system, the workers' collective is based on a culture of resistance that attempts to gain informal control over the work situation. It can also function as a protector of practical and hard physical work (cf. Willis, 1979), referred to as 'embodied competence' or 'body capital' (Connell, 1995; Monoghan, 2002). Consequently, new technology and new management models are often resisted by the collective system (Fältholm, 1998). In this context, Industry 4.0, automated factories, and Internet of Things represent a new technological and managerial landscape to which several reactions are possible. There is a need to analyse the opportunities and challenges represented by the current technological and organizational development and to create a theoretical platform for the understanding of the transformation of work and workers based on the workers' collective. 


\section{Crowdsourcing}

Extant research on crowdsourcing has largely focused on the business benefits of the organisations sourcing labour with less attention directed towards worker perspectives or its wider implications on the labour market. Current literature has also focused on knowledge workers on a general level, but so far there are no studies done within an industrial context and none with a focus on its potential impact as we move towards Industry 4.0. One contemporary example of how digitalisation is reshaping the labour market and working practices is that of crowdsourcing where Internet technology and digital platforms are used to source online contributions (Bergvall-Kåreborn \& Howcroft, 2013, 2014). Crowdsourcing targets an online labour force to complete tasks that may previously have been completed by company employees or contractors. Its growing popularity and reach can be attributed to significantly lower labour costs, ease of access to a labour force with a variety of skill, and expertise that can expand and contract on demand, operating in an environment where employment regulation and protection is deficient (Ross, 2013; Scholtz, 2013). This is a new sector where research must be established.

\section{Human-machine/robot interaction}

Yet another field calling for research is the design of the technology innovations and systems forming Industry 4.0. The research in this area makes it clear that much of the focus lies on the technological development and more specifically on how technology could replace humans. This approach is appropriate as one of the goals is to make machines sense and act without human intervention (Gubbi, Gubbi, Buyya, Marusic, \& Palaniswami, 2013) or with minimal human involvement (Al-Fuqaha, Guizani, Mohammadi, Aledhari, \& Ayyash, 2015). This development stems from a goal to increase effectiveness and reduce humans from dangerous or complex tasks. However, this development could in the end turn out to be ineffective if the human role within the human-machine system is disregarded. If the human role in the system changes, the skill and effectiveness of the human will probably change too. The design of systems and the interplay between human and machines may affect how the work force develops.

A poorly designed system and a transition from active to passive processing, as in monitoring, could reduce situational awareness and put the operator out-of-theloop (Endsley, 2015). As Bainbridge (1983) pointed out, if automation reduces the human work to monitoring, there will be problems with reduced manual control skills, cognitive skills, and vigilance and a risk of ending up with work tasks that are boring although very responsible. Parasuraman, Sheridan, and Wickens (2000) believe there is an added risk when technology is overly-trusted (complacency) and this could eventually add to workload. They argue that a well-designed interface could reduce workload by helping the worker sort and pick relevant information. On the other hand, a "clumsy" interface, one that is hard to engage and that re- 
quires extensive data entering, could increase cognitive and physical workload demands. Another issue is the handling of integrity and privacy. The technology could be used to track users (Roman, Najera, \& Lopez, 2011) and to control workers rather than the process. In a safety critical situation, this type of human tracking might be welcomed, although the information could also be misused. These issues are important to address as technology develops towards the smart factory or Industry 4.0.

Robots as workmates will soon be a reality. A crucial gap that still needs to be filled before robots are integrated in real-world settings is that they must ultimately be accepted by humans in the human social sphere. An essential factor playing a role in acceptance of robots is their ability to react appropriately to human social signals and to follow norms of human behaviour. In short, it is crucial to identify parameters of robot behaviour that allow for social attunement with humans. Here, attunement is understood as the process of engaging brain mechanisms allowing for smooth communication and cooperation. An example of such a mechanism is joint attention. In the context of human-robot interaction, studies using robot faces presented on a computer screen (Wiese, Zwickel, \& Müller, 2012; Wykowska, Wiese, Prosser, \& Müller, 2014; Wzkowska et al. 2015; Wzkowska, Chaminade, \& Cheng 2016) have shown that robots do not evoke joint attention, as other humans do.

\section{Concluding Remarks}

The wolf is coming or God's gift to mankind - that's the question. Judy Wajcman (2017) discusses the question in a new article on automation where she points out that one has always heard that the wolf is coming, but so far no one really has seen it. Our contribution to the discussion has been to highlight the issue from several perspectives. First, we concluded that Industry 4.0 is essentially a technology-driven concept connected to several organizational concepts, where Lean Production is the most powerful. Given the strong influence of Lean Production, Industry 4.0 will require new demands for teamwork, responsibility, and comprehensive understanding of production flow, which can be seen as a movement from qualifications dependent on the process to qualifications more independent of the process. Another and partly contradictory effect is that digitalization allows for a flexible labour market, where labour can be purchased on demand from all parts of the world as long as there is a working Internet connection. Good or bad, there will be significant differences in working conditions between the two alternatives. In the first option, we see the worker embedded in a technological production system where the workplace is a social unit, while the second development is based on individual work through the various types of monitoring and remote control.

Based on our analysis, we addressed four knowledge gaps that need more research in relation to digitized work. 
- The relationship between new technology, working conditions, qualifications, identity, and gender must be explored further from a critical perspective

n The future of the workers' collective in a digitalized working life needs to be studied.

- Crowdsourcing in an industrial context is a new sector where research is lacking.

- Human-machine interaction must be explored further with a focus on integrity issues.

There are many positive aspects of Industry 4.0 and Internet of Things, probably most of the parts, but there are many questions that must be clarified. The development cannot and should not be stopped, but it requires reflections and considerations so we do not create more problems than we solve. Research has an important role to play when new technology should be valued and introduced, but that role is not pre-given to us; we have to mark our position by highlighting issues that are perceived as important and relevant. A first step is to ask the right questions.

\section{References}

Abrahamsson, L. (2006). Exploring construction of gendered identities at work. In S. Billet, T. Fenwick, \& M. Somerville (Eds.), Work, subjectivity and learning. Understanding learning through working life (105-121). Dordrecht: Springer.

Abrahamsson, L. (2009). Att återställa ordningen [To restore the scheme]. Umeå: Boréa Bokförlag.

Abrahamsson, L., \& Johansson, J. (2006). From grounded skills to sky qualifications, Journal of Industrial Relations, 48(5), 658-676.

Abrahamsson, L. (2014). Gender and the modern organization. Ten years after. Nordic Journal of Working Life Studies, 4(4), 109-136.

Acker, J. (1990). Hierarchies, jobs, bodies. Gender and Society, 4(2), 139-158.

Al-Faqaha, A., Guizani, M., Mohammadi, M., Aledhari, M., \& Ayyash, M. (2015). Internet of Things: A survey on enabling technologies, protocols, and applications. IEEE Communication Surveys \& Tutorials, 17(4), 2347-2376.

Alam, M. M., \& Hamida, E. B. (2014). Surveying wearable human assisteive technology for life and safety critical applications. Sensors, 14(5), 9153-9209.

Andersson, E. (2012). Malmens manliga mysterium [Malmen's male mystery] (PhD theses). Luleå tekniska universitet, Luleå.

Bainbridge, L. (1983). Ironies of automation. Automatica, 19(6), 775-779.

Bartneck, C., Kulic, D., \& Croft, E. (2009). Measurement instruments for the anthropomorphism, animacy, likeability, perceived intelligence, and perceived safety of robots. International Journal of Social Robotics, 1(1), 71-81.

Bergvall-Kåreborn, B., \& Howcroft, D. (2013) The future's bright, the future's mobile: A study of Apple and Google mobile application developers. Work, Employment and Society, 27(6), 964-981.

Bergvall-Kåreborn, B., \& Howcroft, D. (2014). Amazon mechanical turk and the commodification of labour. New Technology, Work and Employment, 29(3), 213-223. 
Berner, B. (2003). Vem tillhör tekniken? Kunskap och kön i teknikens värld [Who belongs to the technology? Knowledge and gender in the technology world]. Lund: Arkiv.

Bickmore, T. W., \& Cassell, J. (1999). Small talk and conversational storytelling in embodied interface agents. In M. Mateas \& P. Sengers (Eds.), Proceedings of the AAAI Fall Symposium on Narrative Intelligence (87-92). Menlo Park, CA: AAAI Press.

Blauner, R. (1964). Alienation andfreedom. Chicago, IL: UCP.

Braverman, H. (1974). Labour and monopoly capital. New York, NY: Monthly Review Press.

Breazeal, C. (2002). Designing sociable robots. Boston, MA: MIT Press.

Bright, J. (1958). Automation and management. Boston, MA: Harvard Business School.

Butler, J. P. (1990). Gender Trouble: feminism and the subversion of identity. New York, NY: Routledge.

Butler, J. P. (1993) Bodies that matter: on the discursive limits of "sex". New York, NY: Routledge.

Cabibihan, J. J., So, W. C., Saj, S., \& Zhang, Z. (2012). Telerobotic pointing gestures shape human spatial cognition. International Journal of Social Robotics, 4(3), 263-272.

Collinson, D. (1992). Managing the shop floor. Berlin: Walter de Gruyter.

Collinson, D., \& Hearn, J. (Eds.) (1996). Men as managers, managers as men. London: Sage.

Connell, R. W. (1995). Masculinities. Los Angeles, CA: University of California Press.

Dombrowski, U., \& Wagner, T. (2014). Mental strain as field of action in the 4th industrial revolution, Procedia CIRP, 17, 100-105.

Ely, R. J., \& Meyerson, D. (2008). Unmasking manly men. Harvard Business Review, 86(7/8), 20.

Embgen, S., Luber, M., Becker-Asano, C., Rigni, M., Evers, V., \& Arras, K.O. (2012). Robot specific social cues in emotional body language. In Institute of Electrical and Electronics Engineers [IEEE] (Ed.), Proceedings of the IEEE International Symposium on Robot and Human Interactive Communication (RO-MAN'12) (1019-1025). Red Hook, NY: IEEE.

Endsley, M. R. (2015). Situation awareness: Operationally necessary and scientifically grounded. Cognition, Technology \& Work, 17(2), 163-167.

Eveline, J. (1989). Patriarchy in the diamond mines (Unpublished honours thesis). Perth: Murdoch University Australia.

Eveline, J. (2001). "Keeping the boys happy": Managerialism and the resistance of women miners in Australia. Paper presented at the Gender, Work and Organization Conference, University of Keele, UK.

Eveline, J., \& Booth, M. (2002). Gender and sexuality in discourses of managerial control, Gender, Work and Organization, 9(5), November 2002.

Fältholm, Y. (1998). Work, cooperation and professionalization (PhD theses). Luleå University of Technology, Luleå.

Feki, M.A., Kawsar, F., Boussard, M. \& Trappeniers, L. (2013). The Internet of Things: The next technological revolution. Computer, 46(2), 24-25.

Fenwick, T. (2005). Learning as grounding and flying: Knowledge, skill and transformation in changing work contexts. Paper presented at the conference: From grounded skills to sky qualifications, 17-19 August 2005, Kiruna, Sweden.

Furusten, S., (1996). Den populära managementkulturen [Den populära managementkulturen]. Stockholm: Nerenius \& Santérus. 
Gherardi, S. (1994). The gender we think, the gender we do in our everyday organisational lives. Human Relations, 47(6), 519-610

Gherardi, S. \& Nicolini, D. (2000). The organizational learning of safety in communities of practice. Journal of Management Inquiry, 9(1), 7-18.

Gill, S. (2014, June 23). Industry prepares for the next industrial revolution. Control Engineering. Retrieved from http://www.controleng.com/single-article/industry-prepares-for-the-next-industrial-revolution/6a00860f7b0971 e42ea1a9a7114468e4.html

Gonsior, B., Sosnowski, S., Mayer, C., Blume, J., Radig, B., Wollherr, D. \& Kühnlenz, K. (2011). Improving aspects of empathy and subjective performance for HRI through mirroring facial expressions. RO-MAN, 350-3.

Gubbi, J., Buyya, R., Marusic, S. \& Palaniswami, M. (2013). Internet of Things (IoT): A vision, architectural elements, and future directions. Future Generation Computer Systems, 29, $1645-1660$.

Hammer, M. \& Champy, J. (1993). Reengineering the corporation. New York, NY: Harper Collins.

Häring, M., Eichberg, J., \& André, E. (2012). Studies on grounding with gaze and pointing Gestures in human-robot-interaction. In S. S. Ge, O. Khatib, J.-J. Cabibihan, R. Simmons, \& M. A. Williams (Eds.), Social Robotics. Proceedings of the 4th International Conference on Social Robotics (ICSR 2012) (378-387). Heidelberg: Springer.

Hasle, P., \& Sörensen, O.H. (2013). Employees as individually and collectively acting subjects Key contributions from nordic working life research. Nordic Journal of Working Life Studies, 3(3) 2013.

Hirdman, Y. (1988). Genussystemet: Reflexioner över kvinnors sociala underordning [Gendersystem: Reflections on women's social subordination]. Kvinnovetenskaplig tidskrift KVT, 3, 49-63.

Hirdman, Y. (2001). Genus - om det stabilas föränderliga former . [Gender - About the changing forms of stability]. Malmö: Liber.

Hollway, W. (1996). Masters and men in the transition from factory hands to sentimental workers. In D. Collinson, \& J. Hearn (Eds.), Men as managers, managers as men (25-42). London: Sage.

Holtgrewe, U. (2014). New, new technologies. New Technology, Work and Employment, 29(1), 924.

Hoonakker, P., \& Korunka, C. (2014). Introduction. In C. Korunka \& P. Hoonakker (Eds.), The impact of ICT on quality of working life (1-7). Dordrecht: Springer.

Howe, J. (2008). Crowdsourcing. New York, NY: Crown Publishing Group.

Johansson, J. (1986). Teknisk och organisatorisk gestaltning (PhD theses). Luleå tekniska universitet, Luleå.

Johansson, J., Abrahamsson, L., \& Johansson, S. (2013). If you can't beat them, join them? The Swedish trade union movement and lean production. Journal of Industrial Relations, 55(3), 445-460.

Johansson, B., Johansson, J., \& Abrahamsson, L. (2010). Attractive workplaces in the mine of the future: 26 statements. International Journal of Mining and Mineral Engineering, 2(3), 239-252.

Johansson, J., \& Abrahamsson, L. (2009). The good work. Applied Ergonomics, 40(4), 775-780.

Johny, B., \& Anpalagan, A. (2014). Body are sensor networks. IEEE Potentials, 33(2), 21-25.

Kagerman, H., Wahlster, W., \& Helbig, J. (2013). Recommendations for implementing the strategic initiative Industry 4.0. München: Acatech. 
Kern, H., \& Schumann, M. (1974). Industriearbeit und Arbeiterbewusstsein [Industrial work and worker awareness]. Frankfurt am Main/Köln: EVA.

Kern, H., \& Schumann, M. (1987). Limits of the division of labour. Economic and Industrial Democracy, 8(2), 151-170.

Köhler, H. D. (2016). Reconstruction and restoration: The legacies of post-war German industrial sociology. Work, Employment and Society, 30(6), 1-13.

Kopacek, P. (2015). Automation and TECIS. IFAC-Papers-OnLine, 48(24), 21-27.

Kühnlenz, B. (2013). Increasing helpfulness towards a robot by emotional, adaption to the user. International Journal of Social Robotics, 5, 457-476.

Lahiri-Dutt, K. (2007). Roles and status of women in extractive industries in India: Making a place for a gender-sensitive mining development. Social Change, 37(4).

Lahiri-Dutt, K. (2012). Digging women: Towards a new agenda for feminist critiques of mining. Gender, Place and Culture, 19(2), 193-212.

Lasi, H., Fettke, P. D. P., Kemper, H. G., Feld, D. I. T., \& Hoffmann, D. H. M. (2014). Industry 4.0. Business \& Information Systems Engineering, 6(4), 239-242.

Lee, J., Kao, H. A., \& Yang, S. (2014). Service Innovation and smart analytics for Industry 4.0 and big data environment. Procedia CIRP, 16, 3-8.

Lindgren, G. (1985). Kamrater, kollegor och kvinnor. [Comrades, colleagues and women] (PhD theses). Sociologiska institutionen, Umeå universitet, Umeå.

Lysgaard, S. (1961). Arbeiderkollektivet [The workers' collective]. Oslo: Universitetsforlaget.

Mattar, N., \& Wachsmuth, I. (2012). Small talk is more than chit-chat. Lect Notes Comput SCKI 2012: Advances in Artificial Intelligence, 7526, 119-130.

Mellström, U. (2004). Machines and masculine subjectivity, technology as an integral part of men's life experiences. Masculinities and Technology, 6(4), , 368-383.

Monoghan, L. F. (2002). Hard men and shop boys and others. Oxford: Blackwell Publishing.

Nomura, T., Suzuki, T., Kanda, T., \& Kato, K. (2006). Measurement of negative attitudes toward robots. Interaction Studies, 7(3), 437-454.

Olofsson, J. (2010). Taking place - augmenting space (PhD theses). Luleå University of Technology, Luleå.

Parasuraman, R., Sheridan, T. B., \& Wickens, C.D. (2000). A model for types and levels of human interaction with automation. EEE Transactions on Systems, Man, and Cybernetics - Part A: Systems and Humans, 30(3), 286-297.

Polanyi, M. (1967). The tacit dimension. London: Routledge.

Regeringskansliet (2016). Smart Industry - a strategy for new industrialisation for Sweden. Stockholm: Government Offices of Sweden

Roman, R., Najera, P., \& Lopez, J. (2011). Securing the Internet of Things. Computer, 44(9), 51-58.

Romero, D., Stahre, J., Wuest, T., Noran, O., Bernus, P., Fast-Berglund, Å., \& Gorecky, D. (2016). Towards an operator 4.0 typology: A human-centric perspective on the fourth industrial revolution technologies. In Computers \& Industrial Engineering [CIE] (Ed.), 46th International Conference on Computers \& Industrial Engineering 2016 (CIE46) Proceedings (608-618). Los Angeles, CA: CIE. 
Ross, A. (2013). In search of the lost paycheck. In T. Scholz (Ed.), Digital labor (13-32). London: Rutledge.

Røvik, K. A. (2003). The secrets of the winners. In K. Sahlin-Andersson \& L. Engwall (Eds.), The expansion of management knowledge (113-144). Stanford, CA: Stanford University Press.

Scholtz, T. (Ed.) (2013). Digital labor. London: Rutledge.

Somerville, M., \& Abrahamsson, L. (2003). Trainers and learners constructing a community of practice. Studies in the Education of Adults, 35(1), 19-34.

Stock, T., \& Seliger, G. (2015). Opportunities of sustainable manufacturing in Industry 4.0. Procedia CIRP, 40, 536-541.

Taylor, P. (2010). The globalization of service work. In P. Thompson \& C. Smith (Eds.), Working life (244-268). London: Palgrave MacMillan.

Thompson, P. (2013). Financialization and the workplace. Work, Employment and Society, 27(3), 472-488.

Wajcman J. (2017) Automation: Is it really different this time? The British Journal of Sociology, 68(1), 119-127.

Wenger, E. (1998). Communities of practice. Cambridge, NY: Cambridge University Press.

West, C. \& Zimmerman, D. H. (1987). Doing gender. Gender and Society, 1(2), 125-151.

West, C. \& Zimmerman, D. H. (2009). Accounting for doing gender. Gender \& Society, 23(1), 112-122.

Whitehead, S. M. (2002). Men and masculinities. Cambridge: Polity Press.

Wiese, E., A., Zwickel, J., \& Müller, H. J. (2012). I see what you mean. PLOS ONE, 7(9), 1-7.

Willis, P. (1979). Shop flour culture, masculinity and the wage form. In J. Clark, C. Chricher \& R. Jonson (Eds.), Working class culture, (185-198). London: Hutchinson.

Wykowska, A., Chaminade, T., \& Cheng, G. (2016). Embodied artificial agents for understanding human social cognition. Philosophical Transactions of the Royal Society London: B. Biological Sciences, 371(1693), 1-9.

Wykowska, A., Kajopoulos, J., Obando-Leitón, M., Chauhan, S., Cabibihan, J. J., \& Cheng, G. (2015). Humans are well tuned to detecting agents among non-agents. International Journal of Social Robotics, 7(5) 767-781.

Wykowska, A., Wiese, E., Prosser, A., \& Müller, H.J. (2014). Beliefs about the minds of others influence how we process sensory information. PLOS ONE, 9(4), 1-11.

Yao, X., Jin, H., \& Zhang, J. (2015). Towards a wisdom manufacturing vision. International Journal of Computer Integrated Manufacturing, 28(12), 1291-1312. 